\title{
Curcumin encapsulation using dendrimer PAMAM G4 conjugated with polyethylene glycol to improve the properties of gel dossage form
}

\author{
Rahmah Elfiyani*, Yudi Srifiana, Faisal Dharojat Al Rasyied \\ Faculty of Pharmacy and Science, University of Muhammadiyah Prof. DR. HAMKA \\ Jl. Delima II/IV Klender Jakarta Timur Indonesia
}

Submitted: 14-02-2018

Reviewed: 08-03-2018

Accepted: 08-05-2018

\begin{abstract}
Curcumin has a low bioavailability, therefore it needs to be encapsulated in the PAMAM dendrimer conjugated PEG to improve its bioavailability. To facilitate topical use, curcumin dendrimer was combined with a carbomer 940 that can produce hydration conditions in the stratum corneum to increase the bioavailability of curcumin. This study aimed to obtain the ratio between curcumin and dendrimer of PEG-conjugated PAMAM G4 in gel dosage form to produce the optimal of physical characteristics of dendrimer and physical stability of gel. The first step of this study was the formation of dendrimer of PEG-conjugated PAMAM G4 by using a ratio of 1: 5, and then encapsulated curcumin in dendrimer with a ratio of 1:0.2 (F1); 1:0.02 (F2) and 1:0.002 (F3). The next step was dendrimers formulated in a gel with a carbopol base 940. Evaluation of gel's physical characteristics were polydispersity index, zeta potential, particle size, organoleptic, flow properties, and $\mathrm{pH}$ at weeks $0,2,4$ and 6 . The results shows that $\mathrm{F} 1$ has zeta potential highest and the lowest viscosity of the other formula, while F3 has the lowest potential zeta and highest viscosity of other formulas. In addition, the polydispersity index, particle size, organoleptic, flow properties and $\mathrm{pH}$; there are not a significant difference in each formula, but the particle size, zeta potential, and viscosity of gel can decrease with longer storage time. Conclusion of this study that the ratio $1: 0.2$ of curcumin and dendrimer of PEGconjugated PAMAM G4 shows the optimal of physical characteristics of dendrimer and physical stability of gel.
\end{abstract}

Keywords: curcumin, PAMAM G4 conjugated PEG, physical characteristic, gel

\footnotetext{
Corresponding author:

Rahmah Elfiyani

Faculty of Pharmacy and Science, Muhammadiyah University Prof. DR. HAMKA

J1. Delima II/IV Klender Jakarta Timur

Email: rahmahelfiyani@uhamka.ac.id
} 


\section{INTRODUCTION}

The previous study found curcumin dendrimer using $4^{\text {th }}$ generation of poliamidoamine (PAMAM G4) with ratio 0,02:1 in a gel dosage form with gelling agent carbopol 940 showing the best characteristic and diffusion rate (Lanimarta, 2012; Perdana, 2012). However PAMAM G4 has a positively charged outer group $\left(-\mathrm{NH}_{2}\right)$, therefore it is necessary to modify the outermost group of PAMAM by conjugation reaction with a neutral or negatively charged polymers (Jain et al., 2010). Dendrimer with negatively or neutral charged in the outer group with relatively small sizes may diffuse directly through membrane cells without causing any damage, otherwise dendrimer with size more than $500 \mathrm{~nm}$ or have outer group in the form of positively charged can cause cells damage due to positively charged on the outer group will bind with lipid layer in cell membranes and induce the formation of holes in cell membranes (Hong et al., 2004).

Poliethylene glycol (PEG) is a polymer that can be conjugated with PAMAM to modify the outer group of dendrimer, moreover it is biodegradable and therefore safe to use in drug delivery system. PAMAM whose outer group has been conjugated with $8 \%$ PEG showed the best diffusion rate as drug and genes delivery in mice (Qi et al., 2009).

Physical characteristics and diffusion of dendrimer of PEG-conjugated PAMAM G4 which encapsulates curcumin in carbopol 940 base will be different from the physical characteristics of dendrimer itself. Based on previous studies, it will be developed by modifying the outer group PAMAM G4 by conjugating using PEG to encapsulate curcumin and combining the dendrimer in gel with carbopol 940 base.

The purpose of this study was to obtain the ratio between curcumin and dendrimer of PEGconjugated PAMAM G4 in gel dosage form to produce the optimal of physical characteristics of dendrimer and physical stability of gel.

\section{MATERIALS AND METHODS}

\section{Materials}

Materials that used is PAMAM G4 dendrimer pro-analyst (Dendritech), curcumin pro-analyst (Insular Multi Natural), MPEG (Methoxy Polyethylene Glycol) pro-analyst (Sigma Aldrich), triethanolamine (TEA) pro-analyst (Merck), 4-nitrophenyl-chloroformate (NPC) pro-analyst (Sigma Aldrich), and carbopol 940 (Lubrizol).

\section{Method}

Synthesis of NPC-conjugated MPEG (Qi et al., 2009)

A total of $10 \mathrm{~g}$ of MPEG was dissolved in $400 \mathrm{ml}$ of THF, then added with $0.8062 \mathrm{~g}$ of NPC and $0.5576 \mathrm{ml}$ triethylamine gradually for 1 hour with the aid of stirring (the materials were reacted on a molar ratio of $0.5: 1: 1$ ), the container was closed and then stirred using a magnetic stirrer for 2 days. Subsequently the solution was put into the vacuum rotary evaporator for evaporating the solvent and the concentrated liquid dissolved with 300-400 ml solvent (chloroform and diethyl ether) at a molar ratio 10: 1 in the erlenmeyer to be recrystallized by heating at $50^{\circ} \mathrm{C}$, then cooled in an ice shaft to form a crystals of NPC-conjugated PEG. 

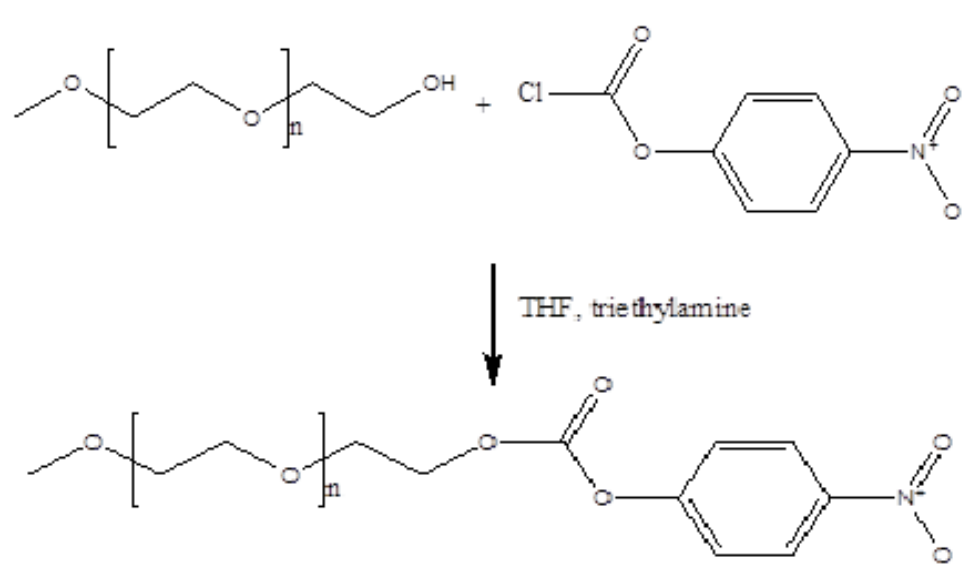

Figure 1. The synthesis reaction of NPC-conjugated MPEG (Qi et al., 2009)

\section{Synthesis of dendrimer of PEG-conjugated PAMAM G4 (Qi et al., 2009)}

As much as $3 \mathrm{~g}$ PAMAM G4 in methanol had been evaporated, then PAMAM G4 was dissolved in 60-70ml DMSO and mixed with 5,276g of NPC-conjugated PEG, then stirred using magnetic stirrer for 5 days. Afterwards dialysis was performed to isolate the PEG-conjugated PAMAM G4 for 3 days and evaporated the solvent by the freeze drying method.

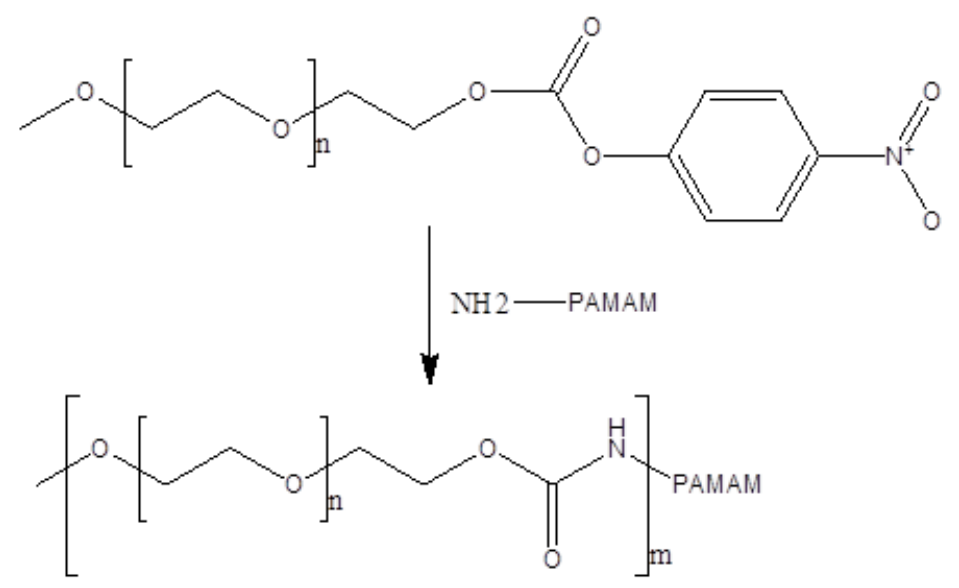

Figure 2. The synthesis reaction of PEG-conjugated PAMAM dendrimers (Qi et al., 2009)

FTIR spectrum analysis of dendrimer of PEG-conjugated PAMAM G4 (Ferraro and Khrisnan, 1990)

The samples were placed on the FTIR analysis ring. Thereafter adjusted the wavelength at 400 $40,000 \mathrm{~cm}^{-1}$, then the FTIR analysis ring which has been inserted by the sample is pressed with the top press on the FTIR. Then performed spectral reading on the sample and performed analysis on the functional group that showed the formation of conjugation between 2 compounds. 
Encapsulation of curcumin in PEG-conjugated PAMAM G4 with ratio 1:0.2 (F1); 1:0,02 (F2) and 1:0,002 (F3) (Ditjen POM, 2014; Perdana, 2012; Markatou et al., 2007)

Curcumin was first dissolved in methanol in a $100 \mathrm{ml}$ flask (M1), PEG-conjugated PAMAM G4 was dissolved in methanol and then fed into M1 and sufficient it to the border mark at the flask. Each formula was stirred with a magnetic stirrer for 24 hours. Followed by removing the methanol solvent on each formula, then each formula was dissolved with phosphate buffer $\mathrm{pH} 7.4$ as much as $10 \mathrm{ml}$ then stirred with a magnetic stirrer for 24 hours. Furthermore, the separation between free curcumin and curcumin trapped in PEG conjugated PAMAM G4 on samples F1, F2 and F3 using ultracentrifugation for 30 minutes at $4^{\circ} \mathrm{C}$ at $50.000 \mathrm{rpm}$ to obtain supernatant, then drying supernatant with freeze drying method.

\section{Morphology dendrimer curcumin of PEG-conjugated PAMAM G4 (Perdana, 2012)}

A total of $25 \mathrm{mg}$ of sample was dispersed with ethanol in a $50 \mathrm{ml}$ measuring flask, then 1 drop of solution dripped onto a carbon-coated copper-grid sheet on TEM. The morphological particle images of the PEG-conjugated PAMAM G4 that encapsulate curcumin were taken at magnification 150,000 times, 80,000 times and 20,000 times at $120 \mathrm{kV}$ voltage.

\section{Determination of drug loading and encapsulation efficiency (EE) of curcumin in dendrimer of PEG-conjugated PAMAM G4 (Perdana, 2012)}

The precipitate obtain from ultracentrifugation (curcumin not trapped in dendrimer) was dissolved again in methanol, then determined the absorbance by using UV-Vis spectrophotometer at maximum wavelength of curcumin was $422,4 \mathrm{~nm}$.

$\% \mathrm{EE}=[($ total curcumin weight - free curcumin weight $) /$ total curcumin weight $] \times 100 \%$,

Drug loading $(\mathrm{b} / \mathrm{v})=[($ total curcumin weight - free curcumin weight $) /$ total curcumin volume $]$

\section{Preparation of gel dendrimer of PEG-donjugated PAMAM G4 that encapsulated curcumin (Ditjen POM, 2014; Lanimarta, 2012)}

Carbopol 940 was dispersed in aquadest and propylene glycol at $500 \mathrm{rpm}$, then dispersion was dripped with TEA sufficiently until gel base is formed. Thereafter, $300 \mathrm{mg}$ PEG-conjugated PAMAM G4 that encapsulated curcumin (the result of freeze drying) was incorporated into the gel base which was formed and stirred homogeneously with homogenizer at $500 \mathrm{rpm}$, then methyl paraben was dissolved in propylene glycol and mixed in a gel base with the aid stirring using homogenizer at 500 $\mathrm{rpm}$ to homogeneous. After all the active substances are dispersed homogeneously, the gel is given phosphate buffer $\mathrm{pH} 6.0$ to a constant gel $\mathrm{pH}$ at $\mathrm{pH}$ 6.0. The last step was to sufficiently the gel with aquadest until the desired weight in formula.

Table I. Formula of gel dendrimer curcumin

\begin{tabular}{cccc}
\hline & F1 & F2 & F3 \\
\hline Curcumin - Dendrimer (1:0.2) & $1 \%$ & - & - \\
Curcumin - Dendrimer (1:0.02) & - & $1 \%$ & - \\
Curcumin - Dendrimer (1:0.002) & - & - & $1 \%$ \\
Carbopol 940 & $1 \%$ & $1 \%$ & $1 \%$ \\
TEA & qs pH 9.0 & qs pH 9.0 & qs pH 9.0 \\
Phosphate buffer pH 6.0 & qs pH 6.0 & qs pH 6.0 & qs pH 6.0 \\
Propylene glycol & $15 \%$ & $15 \%$ & $15 \%$ \\
Methyl paraben & $0.3 \%$ & $0.3 \%$ & $0.3 \%$ \\
Aquadest & ad 30g & ad 30g & ad 30g \\
\hline
\end{tabular}




\section{Determination of curcumin content in gel of curcumin dendrimer (Lanimarta, 2012)}

A total of $1.0 \mathrm{~g}$ of gel was dissolved with methanol in a $25 \mathrm{ml}$ measuring flask, then the suspension was filtered. Furthermore, $1 \mathrm{ml}$ filtrate was dissolved with methanol in a $10 \mathrm{ml}$ measuring flask. After that, the absorbance of the samples was determined using a UV-Vis spectrophotometer at maximum curcumin wavelength.

\section{Evaluation of gel of curcumin dendrimer (Helal et al., 2012)}

Evaluation of average particle size, polydispersity index, and zeta potential was performed using PSA by dispersing the $10 \mathrm{mg}$ sample with water in $100 \mathrm{ml}$ measuring flask, then the sample was inserted into the flow cell, then the reading was done at $25^{\circ} \mathrm{C}$ for 10 minutes with each reading yields 10 data, then the average of the data was calculated. This evaluation was conducted at weeks $0,2,4$ and 6 gel.

In addition, organoleptic, $\mathrm{pH}$, and rheology evaluations were performed on curcumin dendrimer

\section{Data Analysis}

Normally distributed data was analyzed using a two-way analysis of variance (ANOVA) method, while the distributed data is not normal then analyzed using the Friedmann-test method without testing any assumptions.

\section{RESULT AND DISCUSSION FTIR spectrum}

Based on the FTIR spectrum of PEG-conjugated PAMAM G4 seen only 3 peaks, it proves that the inner group of PAMAM G4 is more difficult to read in the presence of PEG that conjugates outer group PAMAM G4 and makes the interior of the dendrimer more protected from external effects of dendrimer. On the FTIR spectrum of PEG-conjugated PAMAM G4 showed a secondary amide bond ($\mathrm{NH})$ has been established which proves that the process of conjugation between PAMAM G4 and MPEG has been successful. Then also showed the primary amide bond (-NH2) indicates that not all outermost groups of PAMAM G4 conjugate with MPEG and it is desirable because if all the outermost groups of PAMAM G4 conjugated with MPEG then curcumin will be difficult to encapsulate into PAMAM G4. Then there is also a small peak indicating that there are hydrocarbon group coming from PAMAM G4 and MPEG (Stuart, 2004)

Table II. Functional groups of PEG-conjugated PAMAM G4 read in FTIR

\begin{tabular}{lll}
\hline & $\begin{array}{l}\text { Distance wave } \\
\text { number }\left(\mathbf{c m}^{-\mathbf{1}}\right)\end{array}$ & $\begin{array}{l}\text { PEG-conjugated PAMAM G4 } \\
(\mathbf{c m})\end{array}$ \\
\hline Secondary amide bond (-NH) & $3300-3250$ & 3268.9 \\
Primary amide bond (-NH2) & $1650-1629$ & 1638.2 \\
Hydrocarbon group & $1275-1000$ & 1013.8 \\
\hline
\end{tabular}




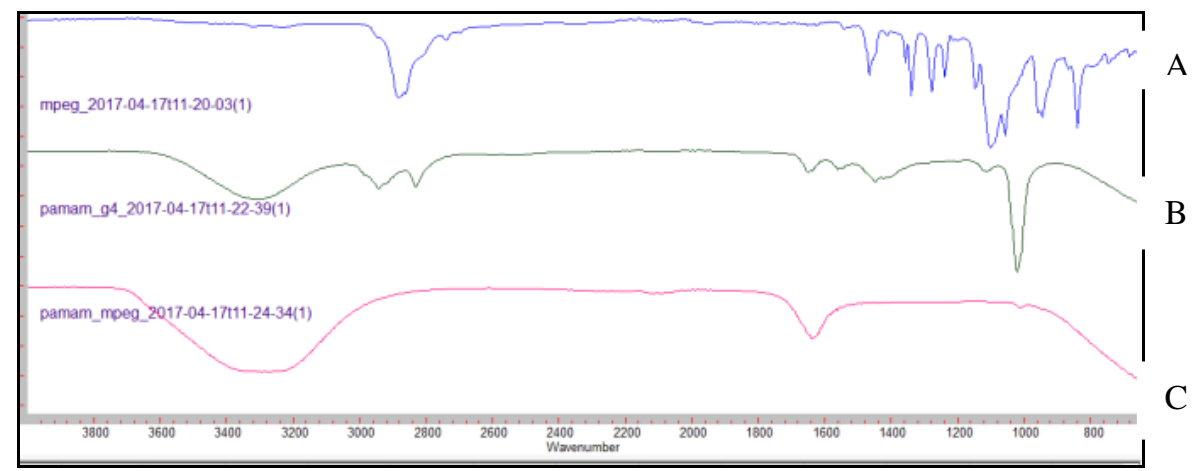

B

$\mathrm{C}$

Figure 3. FTIR spectrum of MPEG (A), PAMAM G4 (B) and PEG-Conjugated PAMAM G4 (C)

Based on the FTIR spectrum of PEG-conjugated PAMAM G4 that encapsulated curcumin, it can be seen that there is a secondary amide group that characterizes of PEG-conjugated B AM G4, the peak more indicates that the amide bond is weak. There is also a hydroxy group $(-\mathrm{OH})$. There was a presence of an aliphatic hydrocarbon group as indicated by the presence of PEG which is aliphatic form elongated on the outermost part of PAMAM G4. There was also an alkene bond $(\mathrm{C}=r)$ because of the curcumin already absorbed in the PEG-conjugated PAMAM G4. In the spectrum tl $\mathrm{C}$ is also an aliphatic ketone group which is part of PAMAM G4 and curcumin. Based on the FTIR spectrum it can be seen that in the sampel there are some compound such as curcumin, PEG and PAMAM G4, so it can be seen also that PAMAM G4 successfully conjugated with PEG and also encapsulates the curcumin (Stuart, 2004).

Table III. Functional groups read in FTIR PEG-conjugated PAMAM G4 which encapsulates curcumin

\begin{tabular}{lll}
\hline & $\begin{array}{l}\text { Distance wave } \\
\text { number }\left(\mathbf{c m}^{-1}\right)\end{array}$ & $\begin{array}{l}\text { PEG-conjugated PAMAM G4 } \\
\text { which encapsulates curcumin } \\
\left(\mathbf{c m}^{-1}\right)\end{array}$ \\
\hline Secondary amide group & $3100-3060$ & 3069.5 \\
Hydroxy group (-OH) & 3237.2 & 3237.2 \\
Aliphatic hydrocarbon group & $3000-2800$ & 2883.1 \\
Alkene bond (C = C) & $2260-2100$ & 2338.9 \\
Aliphatic ketone group & $1720-1680$ & 1750.0 \\
\hline
\end{tabular}

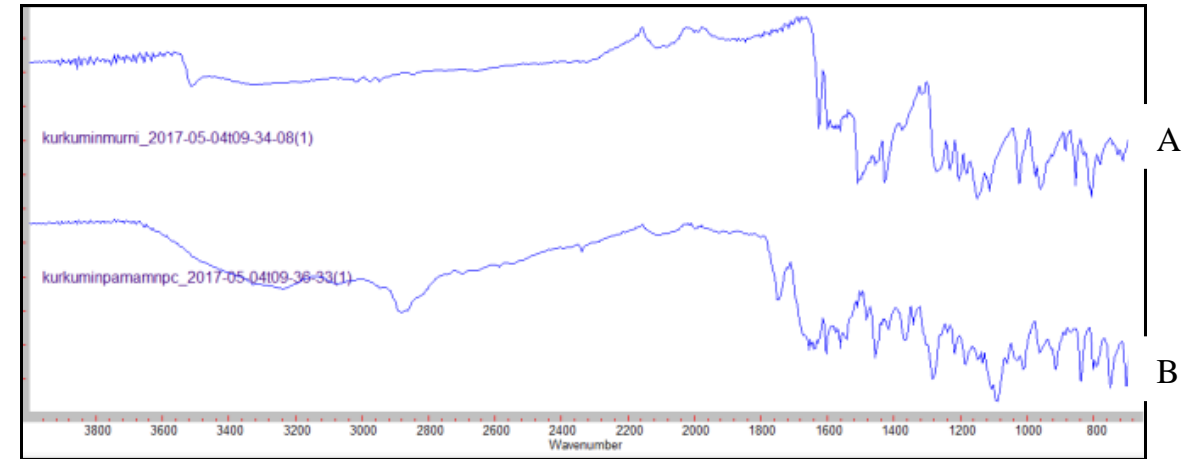

Figure 4. FTIR spectrum of Curcumin (A) and PEG-conjugated PAMAM G4 which encapsulates curcumin (B) 


\section{Morphology of dendrimer curcumin}

The figure 5 showed that ratio 1:0.2, 1:0.02, and 1:0.002 there are similar forms of the dendrimer which tends to be round and there are some black and irregularly elongated parts on the outside of PAMAM G4 that prove the conjugation between outer group PAMAM G4 and PEG. On the other hand, it can be observed that encapsulated curcumin in PEG-conjugated PAMAM G4 through some grayish black or gray spots in dendrimer curcumin.

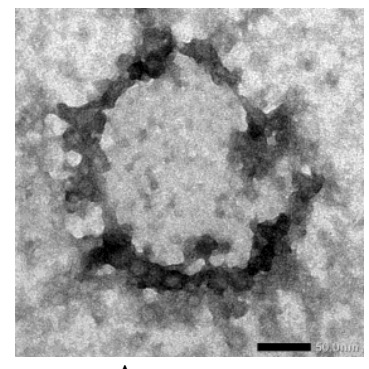

A

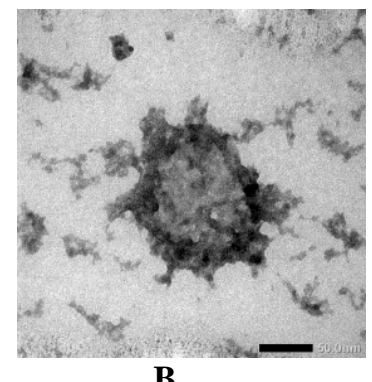

B

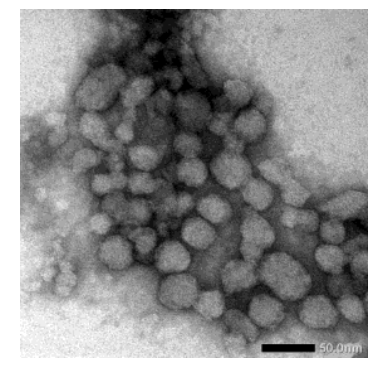

C

Figure 5. PEG-conjugated PAMAM G4 which encapsulates curcumin with ratio 1:0,2 (A), 1:0,02 (B), and 1:0,002 (C)

\section{Drug loading and encapsulation efficiency of curcumin in dendrimer}

Determination of drug loading and encapsulation efficiency in formula 1 is $6.01 \times 10^{-4}$ and $90.5 \%$; formula 2 is $5.21 \times 10^{-4}$ and $79.51 \%$; and formula 3 is $4.55 \times 10^{-4}$ and $69.81 \%$. It can be seen that formula 1 has more encapsulated curcumin. This can happen because the amount of dendrimer concentration is greater than 2 other formulas, so dendrimer can be more to encapsulate curcumin. However, none of the formulas that produce the encapsulation efficiency reaches $100 \%$, proving that a conjugation of PEG may prevent curcumin from being entrapped into the PAMAM G4 as seen in Figure 5 .

\section{Determination of curcumin content in gel dendrimer}

Determination of curcumin content in gel in formula 1 is $0,0110 \%$, formula 2 is $0,0107 \%$ and formula 3 is $0,0100 \%$. The content of curcumin which obtained was very low because the amount of curcumin was mixed only $1 \%$ of the total preparation.

\section{Evaluation of gel of curcumin dendrimer}

It is known that storage time can decrease the size of dendrimer particles. It shows that dendrimer may be degraded or decomposed in its structure over time of storage. Factors that can make dendrimer degraded or decomposed are due to dendrimer storage conditions that are at room temperature. It is known that PAMAM dendrimer can be degraded as much as $15 \%$ if stored for more than 20 days at room temperature, at $4^{\circ} \mathrm{C}$ temperatures the PAMAM dendrimer can still be degraded as much as $9 \%$ if it stored for more than 20 days (Peterson et al., 2001).

Table IV. Particle size of gel of curcumin denrimer

\begin{tabular}{ccccc}
\hline & \multicolumn{4}{c}{ Particle Size* of gel (nm) } \\
\cline { 2 - 5 } & Week 0 & Week 2 & Week 4 & Week 6 \\
\hline Formula 1 & $506.32 \pm 11.33$ & $428.24 \pm 41.13$ & $304.55 \pm 10.18$ & $197.14 \pm 5.19$ \\
Formula 2 & $540.00 \pm 13.35$ & $475.17 \pm 6.03$ & $333.77 \pm 17.69$ & $214.41 \pm 2.53$ \\
Formula 3 & $545.78 \pm 6.50$ & $515.89 \pm 9.06$ & $352.97 \pm 12.46$ & $224.14 \pm 8.33$ \\
\hline$* \mathrm{n}=3$ & & & &
\end{tabular}


The polydispersity index obtain is 0,571 for each formula and each time. This makes the variable cannot be analyzed further and it can be concluded that the duration of gel storage and the difference of formula on dendrimer gel does not affect the polydispersity index. Based on these results show that the gel does not have sufficient good stability because the gel that has good stability should have a polydispersity index less than 0.3 (Das and Chaudury, 2011).

The potential zeta results obtained is relatively large and negatively charged. The high potential zeta indicates that the gel is more stable, because the high charge contained in each similar particle can prevent the dendrimer particles closer together and more stable (Bowman -Boer et al., 2015). Based on the results, the longer duration ofgel storage may cause the potential zeta to increase as well, it is because the dendrimer is lipophilic and non-ionic even after long storage, so it can increase the potential zeta (Bowman-Boer et al., 2015). It affects each formula that has different PEG-conjugated PAMAM concentrations. Formula 1 at week 0 produces the highest potential zeta compared to other formulas because it has a lot of PEG-conjugated PAMAM concentrations as well. Another case with formula 3 which in week 0 produces potential zeta is smaller than any other formula because the PEGconjugated PAMAM concentrations of formula 3 is less than other formulas.

Table V. Potential zeta of gel of curcumin dendrimer

\begin{tabular}{ccccc}
\hline & \multicolumn{4}{c}{ Potential Zeta* of gel } \\
\cline { 2 - 5 } & Week 0 & Week 2 & Week 4 & Week 6 \\
\hline Formula 1 & $-42.02 \pm 0,24$ & $-49.65 \pm 1,99$ & $-47.51 \pm 1.13$ & $-55.46 \pm 0.90$ \\
Formula 2 & $-41.92 \pm 0,71$ & $-51.17 \pm 0,50$ & $-56.79 \pm 0.18$ & $-68.54 \pm 1.26$ \\
Formula 3 & $-39.88 \pm 0,30$ & $-57.65 \pm 1,25$ & $-58.50 \pm 0.17$ & $-72.37 \pm 2.16$ \\
\hline *n
\end{tabular}

It is known from the rheogram that the dendrimer gel flow properties of all formulas are plastic anti-thixotropic. The anti thixotropic flow properties indicate that stirring can change the gel structure which cannot return to its original shape rapidly when the pressure is removed, and the thixotropic system on the gel slowly becomes compacted due to the gentle and uniform stirring. It also proves that the viscosity of the gel is greatly influenced by the timing and speed of the stirring round. There were decrease viscosity with increasing shear rate. Based on the rheological analysis of the three formulas, the gel thickness profile can be known through the shear stress on the gel. This is known because the profile of strength spreading is one of the forms of shear stress applied to semi-solid preparations (Sinko, 2011). In the three formulas can be known if the shear stress gel profile will increase with the speed of stirring speed. Shear stress is the force per unit area required to drain or disperse liquids, so as the shear stress profile increases in the gel as the speed of stirring increases, the gel will spread easily if given a large force when applied. 


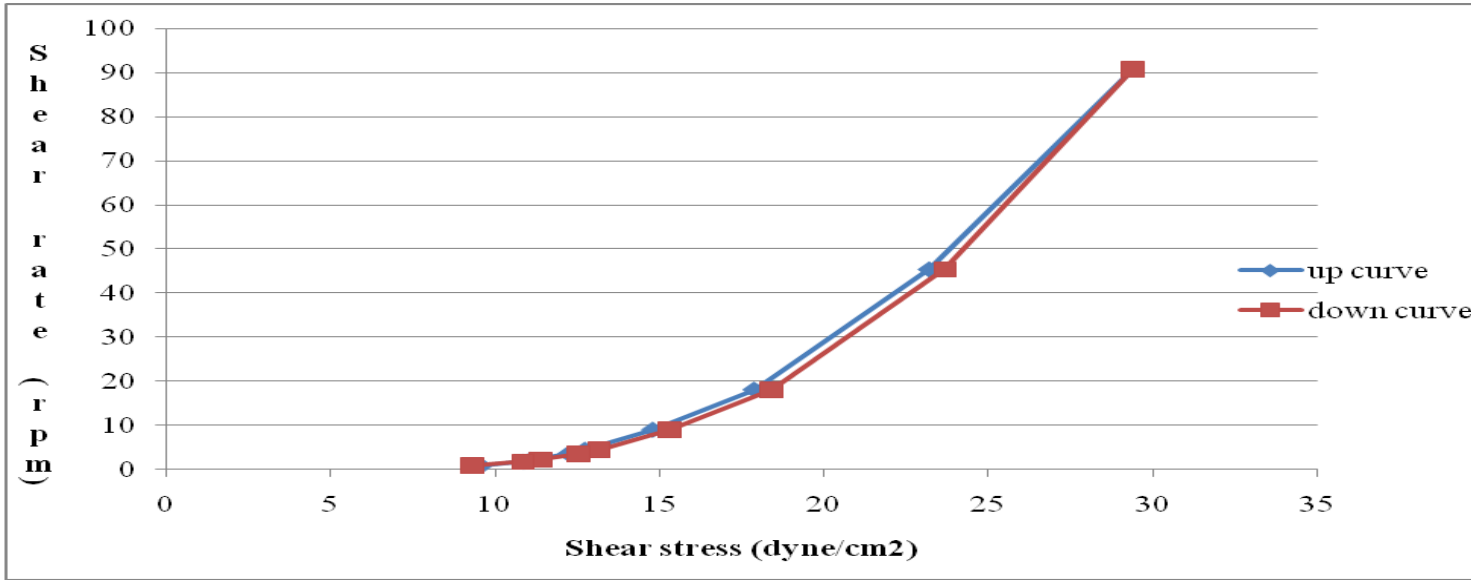

A
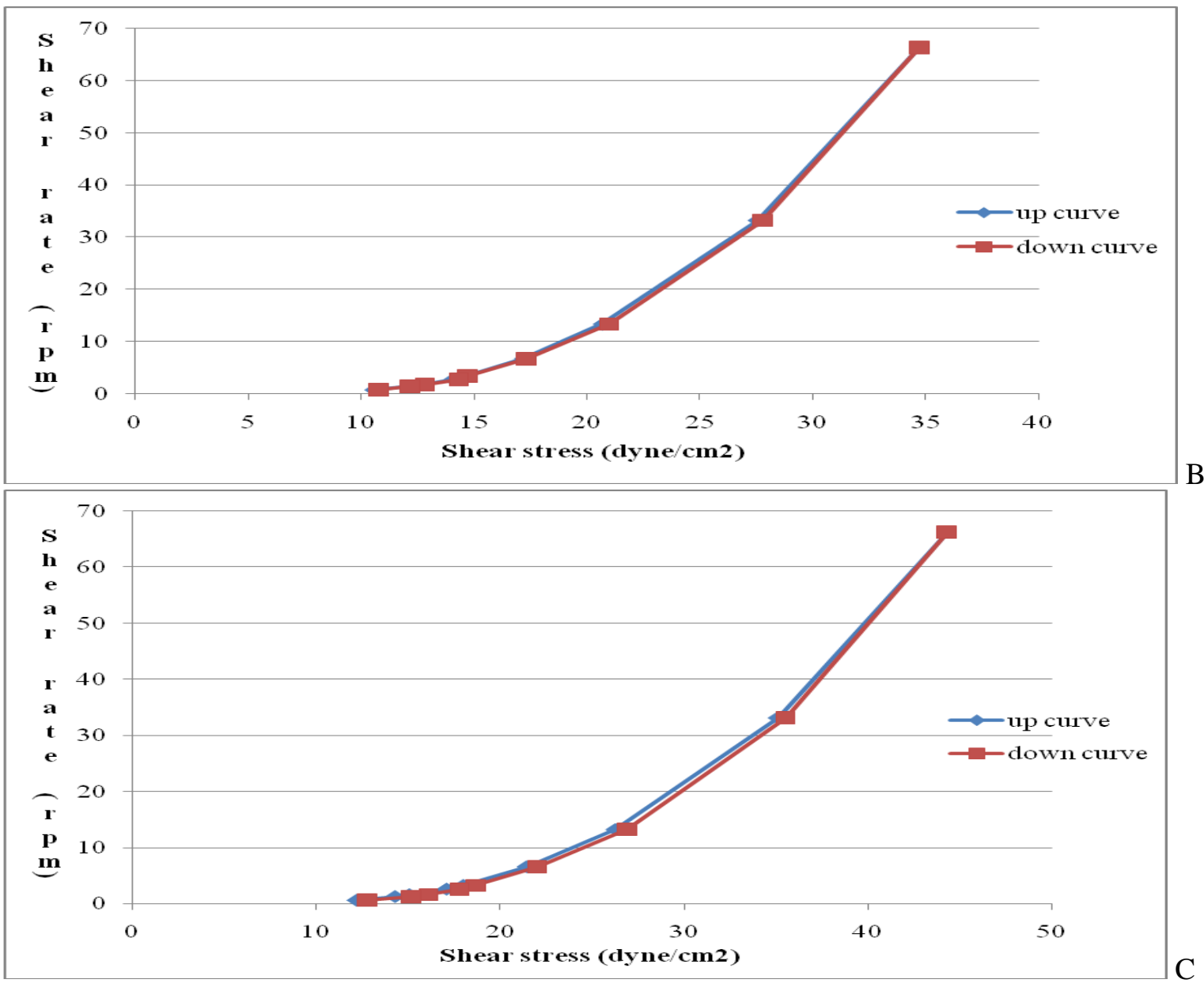

Figure 6. The rheogram of gel of curcumin dendrimer : F1 (A), F2 (B), and F3 (C)

The $\mathrm{pH}$ value of the gel is not influenced by the formula because it uses carbopol 940 at the same concentration so that each formula is adjusted to have the same $\mathrm{pH}$ at the beginning of the manufacturing process. Un-like the case with storage time variables. Changes the $\mathrm{pH}$ on gel showed less stability of the gel during storage. Decomposition of the gel base can cause curcumin out of the gel matrix and into the gel surface, causing curcumin to be degraded or forming another compound that has different acidity levels than curcumin (Young, 1972). 
Table VI. pH of gel of curcumin dendrimer

\begin{tabular}{lcccc}
\hline & \multicolumn{4}{c}{ pH value* of Gel } \\
\cline { 2 - 5 } & Week 0 & Week 2 & Week 4 & Week 6 \\
\hline Formula 1 & $6.8533 \pm 0.0034$ & $6.9122 \pm 0.0039$ & $6.8889 \pm 0.0038$ & $6.7967 \pm 0.0067$ \\
Formula 2 & $6.8533 \pm 0.0034$ & $6.9133 \pm 0.0088$ & $6.8822 \pm 0.0084$ & $6.7978 \pm 0.0019$ \\
Formula 3 & $6.8544 \pm 0.0020$ & $6.9122 \pm 0.0069$ & $6.8866 \pm 0.0058$ & $6.7766 \pm 0.0058$ \\
\hline$*_{\mathrm{n}=3}$ & & \multicolumn{3}{c}{} \\
\hline
\end{tabular}

\section{CONCLUSION}

Based on the results it can be concluded that the optimal ratio of curcumin and dendrimer PAMAM G4 conjugated PEG is 1: 0.2 , because at that ratio is shows the optimal of physical characteristics of dendrimer and the physical stability of the gel.

\section{ACKNOWLEDGEMENTS}

This research can be done because of the assistance and support coming from Lemlitbang UHAMKA and other parties.

\section{REFERENCES}

Bowman-Boer, Y., Fenton-May V., Brun P.,L., 2015. Practical Pharmaceutics: An International Guidline for the Preparation, Care and Use of Medical Producs. Springer, 435-461.

Das, S., Chaudhury A., 2011. Recent Advances in Lipid Nanoparticle Formulations with Solid Matrix for Oral Drug Delivery, AAPS PharmSci Tech, 12 (1): 62-76.

Ditjen POM, 2014, Farmakope Indonesia Edisi V. Departemen Kesehatan Republik Indonesia, 32-42.

Ferraro, J.,R., Krishnan K., 1990. Practical Frourier Transform Infrared Spectroscopy Industrial and Laboratory Chemical Analysis. Academia Press, Inc. San Diego, 43-94.

Helal, D.,A., El-Rhman D.,A., Abdel-Halim S.,A., El-Nabarawi M.,A., 2012. Formulation and Evaluation of Fluconazole Topical Gel, International Journal of Pharmacy and Pharmaceutical Science, 4 (5): 176-183.

Hong, S., Bielinska A.,U., Mecke A., Keszler B., Beals J.,L., Shi X., Balogh L., Orr B.,G., Baker J.,R., Holl M.,M.,B., 2004. Interaction of Poly (amidoamin) Dendrimers with Supported Lipid Bilayers and Cell: Hole Relation and the Relation to Transport, Bioconjugate Chemistry, American Chemical Society, 15 (4), 774-782.

Jain, K., Kesharwani P., Jain N.,K., 2010. Dendrimer toxicity: Let's meet the challenge, International Journal of Pharmaceutics, 394 (1-2):122-142.

Lanimarta, Y., 2012. Pembuatan dan Uji Penetrasi Nanopartikel Kurkumin - Dendrimer Poliamidoamin (PAMAM) Generasi 4 dalam Sediaan Gel dengan Menggunakan Sel Difusi Franz, Skripsi, Fakultas Matematika dan Ilmu Pengetahuan Alam Universitas Indonesia.

Markatou, E., Gionis V., Chryssikos G.,D., Hatziantoniou S., Georgopoulos A., Demetzos C., 2007. Molecular interactionbetween dimethoxycurcumin and Pamam dendrimer carriers, International Journal of Pharmaceutics, 339 (1-2): 231-236.

Perdana, Y.,O., 2012. Pembuatan dan Karakterisasi Fisikokimia Nanopartikel Kurkumin-Dendrimer Poliamidoamin (PAMAM) Generasi 4, Skripsi, Fakultas Matematika dan Ilmu Pengetahuan Alam Universitas Indonesia.

Peterson, J., Allikmaa V., Pehk T., Lopp M., 2001. Fragmentation of PAMAM Dendrimers in Methanol. Proc. Estonian Acad. Sci. Chem, 50 (3), 167-172.

Qi, R., Gao Y., Tang Y., He R., Liu T., He Y., Sun S., Li B., 2009. PEG-conjugated PAMAM Dendrimers Mediate Efficient Intramuscular Gene Expression, AAPS Journal, 11 (3): 395-405. 
Sinko P.,J., 2011. Martin's Physical Pharmacy and Pharmaceutical Sciences: Physical Chemical and Biopharmaceutical Principles in the Pharmaceutical Sciences. Lippincott Williams and Wilkins, Baltimore, 849-888.

Stuart, B., 2004. Infrared Spectroscopy: Fundamentals and Applications, John Wiley and Sons Ltd, $71-93$

Young, A., 1972. Practical Cosmetis Science. Mills and Boon, London, 38-40. 
